\title{
Formation of an artificial vagina in a case of testicular feminization
}

\author{
A. E. R. BuCKLE \\ M.B.(Lond.), F.R.C.S., M.R.C.O.G. \\ Consultant, Department of Obstetrics and Gynaecology \\ J. Watson \\ M.A., M.B.(Cantab.), F.R.C.S. \\ Consultant Plastic Surgeon
}

Lewisham General Hospital, London, S.E.13

THE syndrome of testicular feminization is found in persons of female phenotype, which includes female external genitalia, who have primary amenorrhoea; the labia tend to be underdeveloped, the vagina ends blindly and the cervix is absent. Usually pubic and axillary hair is scanty or absent after puberty and breast development is good. The internal genitals are absent or rudimentary and the gonads, which may be intraabdominal or in the inguinal canal, are testes (Morris, 1953). The chromosomes appear normal with XY sex chomosomes. The condition is inherited, either in a sex-linked recessive or sexlimited dominant manner (Taillard \& Prader, 1957).

Although the vagina may be of sufficient length to allow of coitus, this is not always the case. Reports on the surgical correction of the inadequate vagina are rare and we would like to report on the management of a patient with testicular feminization who requested plastic enlargement prior to marriage.

\section{Case report}

The patient, aged 35 years, attended as an outpatient in May 1964. She gave a history of primary amenorrhoea on account of which she had sought advice at another hospital 12 years earlier. At that time she had been told that the uterus was absent and that the vagina was very short; no further investigation was carried out and, although surgical correction was mentioned, no arrangements were made for this to be done. She was now intending marriage and sought advice regarding the possibility of operation to allow of normal marital relations. The family history was negative.

On examination the patient was tall (height $1.9 \mathrm{~m})$, attractive, blonde-haired and of normal female build (see Fig. 1). Pubic and axillary hair was absent, breast development normal and the external genitalia of female type, although the labia majora were underdeveloped. The vagina was short $(2 \mathrm{~cm})$ and blind ending.

\section{Investigations}

Haemoglobin $12 \mathrm{~g} / 100 \mathrm{ml}$; chest $\mathrm{X}$-ray normal ; serum cholesterol $235 \mathrm{mg} / 100 \mathrm{ml}$; urinary 17 - oxosteroids $18.2 \mathrm{mg}$ in $24 \mathrm{hr}$; urinary 17-hydroxycorticoids $23.9 \mathrm{mg}$ in $24 \mathrm{hr}$; pituitary folliclestimulating hormone negative (less than 6 mouse units); buccal smears showed no sex chromatin present. Later analysis showed a chromosome number of 46 with normal XY complement.

With an etablished diagnosis of testicular feminization syndrome, it was decided to attempt plastic vaginal enlargement together with removal of the gonads, because of the risk of malignant change (Morris, 1953). At the time that this patient was originally seen, four other cases of the testicular feminization syndrome (one with a teratoma of the intra-abdominal testis) were under intensive biochemical investigation in the hospital and the patient was therefore further investigated prior to surgery.

\section{Further investigations}

Plasma 17-hydroxycorticoids: at the lower limit of the female range.

Plasma 17-oxosteroids: upper limit of the female range and more typical of levels found in men.

Plasma testosterone levels: in the male range and definitely exceeding the range found in normal females.

Urinary oestrogen levels: at the upper limit of the normal male range, below the average daily amount excreted by a normal female during a complete cycle, but higher than in women with primary amenorrhoea.

The effest of ACTH and HCG administration on the daily excretion of oestradiol $17-\beta$, oestrone and oestriol and on plasma testosterone was estimated before operation.

At the time of operation, blood was obtained from the gonadal venous plexus for the estimation of plasma testosterone levels. The latter level was found to be some ten times higher than levels found in the peripheral plasma. The half-life of testosterone in the plasma was determined and found to be normal. The secretion rates of dehydroepiandrosterone and its sulphate were found to be of male and not female pattern. Full details of these investigations, together with the 


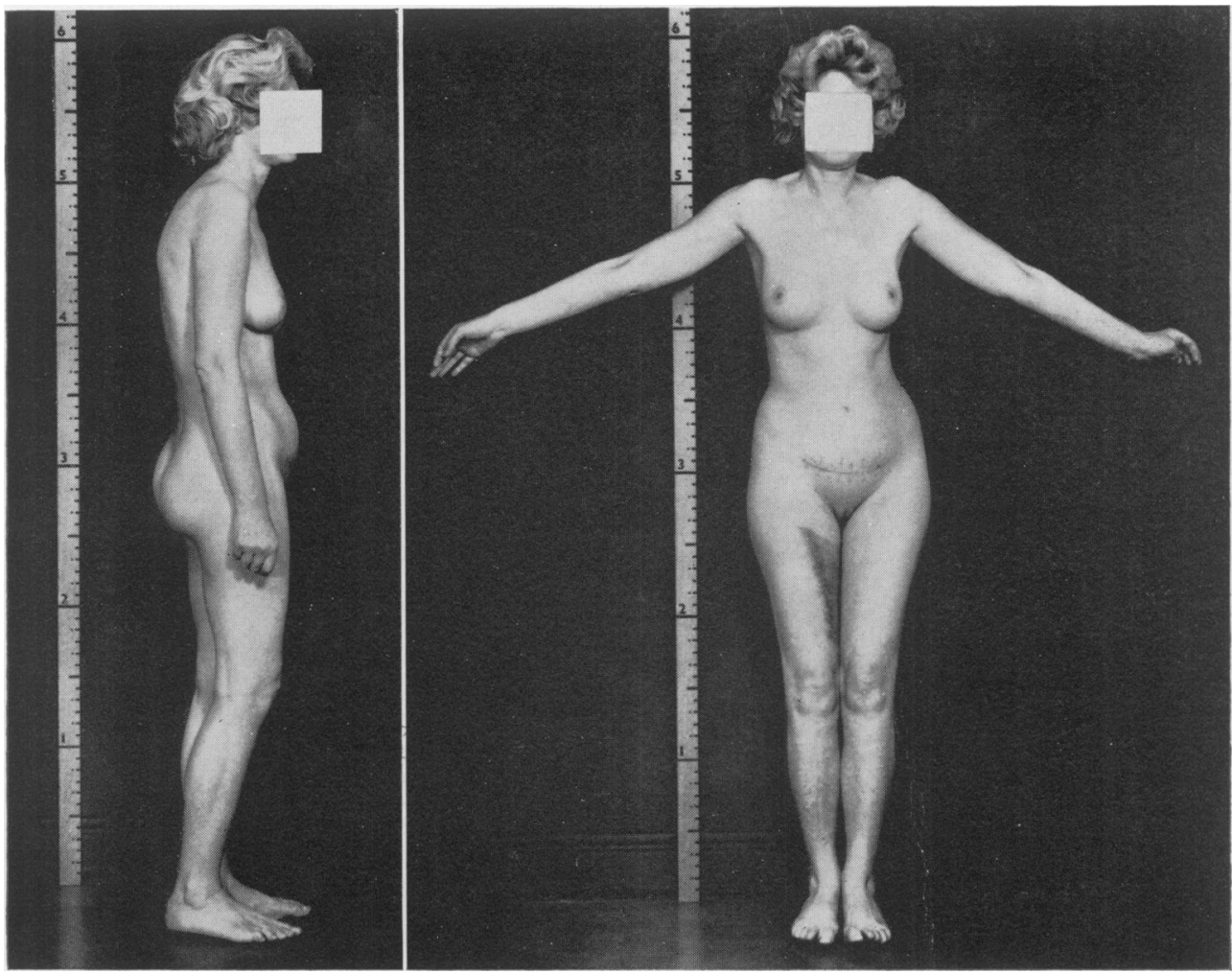

FIG. 1

results from the four other cases of the syndrome mentioned above, have been published elsewhere (Deshpande et al., 1965).

\section{Operation}

After induction of anaesthesia, a split-skin graft was taken from the patient's right thigh. This graft was subsequently sutured to itself, raw surface outwards, over an acrylic resin mould, $15 \mathrm{~cm}$ in length. A solid mould was chosen in this particular instance rather than one constructed of rolled plastic sponge (the technique usually employed) because this was thought safer, for the vault of the new vagina would be in apposition to the pelvic peritoneum; there was thus a possible danger of escape of fragments of sponge into the peritoneal cavity if the graft failed and the peritoneal layer broke down. After the donor site had been dressed, the patient was placed in the lithotomy position.

The apex of the blind-ending vagina was incised transversely and the space between bladder and rectum separated widely in both longitudinal and transverse directions. At the completion of the dissection, the peritoneum could be seen at the apex of the space. Haemostasis was obtained and the cavity sprayed with 'Polybactrin' antibiotic spray. The graft-covered mould was inserted into the space, the labia sutured over the mould and an in-dwelling catheter inserted.

The patient was now positioned for laparotomy. The abdomen was opened through a Pfannenstiel incision and, on entering the peritoneal cavity, the site of the vaginal mould was seen producing a surface elevation of the peritoneum between bladder and rectum. The absence of the uterus and Fallopian tubes was confirmed, the gonad on the left side lying just caudal to the normal ovarian position and the gonad on the right lying at the level of the internal inguinal ring. Blood was obtained from the venous plexus for testosterone estimation, bilateral gonadectomy performed and the abdomen closed in layers.

Post-operatively, the patient was given prophylactic antibiotic cover for 14 days, bladder drainage being continued for a similar period of time. There was a rise in temperature on the 3rd postoperative day, associated with slight purulent loss from the centre of the vaginal mould. The temperature soon subsided and, apart from bowel 
distension, the patient remained well after operation. On the 14th day, she was taken to the operating theatre where the donor site on the right thigh was inspected and re-dressed. Examination of the vagina showed that almost $90 \%$ of the donor skin had taken, there being a small area of granulation tissue at the vault on the right side. The cavity was irrigated with saline and the mould re-inserted without labial suture. Catheter drainage was discontinued at this time.

The patient was discharged from hospital 4 weeks after operation with the mould still in position. She was seen weekly in the out-patient department, the mould being removed at each visit and the vagina inspected. The vault granulations were cauterized and, after 3 months, the use of the acrylic mould was discontinued, the patient being given a size 6 glass dilator to use daily. Stilboestrol $0.5 \mathrm{mg}$ was given daily for 6 months.

\section{Follow-up}

The patient subsequently married and was seen for follow-up 6 months after marriage and 12 months after discharge from hospital. Vaginal examination showed the artificial vagina to be of normal length and healthy. Intercourse was satisfactory and orgasm was achieved.

\section{Histological report (Dr M. O. Skelton)}

'The right testis measures $3 \times 2 \mathrm{~cm}$. At its medial pole is a firm mass of pinkish-yellow tissue having the macroscopic appearance of muscle. On crosssection, the testis is of a dark red-brown colour. There is a cystic hydatid present. Microscopically the testis shows immature seminiferous tubules lined by tall "undifferentiated" epithelial cells with no evidence of spermatogenesis. The interstitial cells are very abundant. At one pole of the testis is a mass of smooth muscle tissue. The left testis measures $2.5 \times 1.5 \mathrm{~cm}$ with a cystic hydatid present. Microscopically the appearances are essentially similar to those of the right testis. There is no evidence of malignant change in either testis.'

In a complete account of the histo-pathological features in this case and in the other four cases mentioned earlier in this paper, McMillan (1966) shows that there has been early cessation of development of the sex cells in the testis and failure of differentiation of the tubular elements whereas, in contrast, the Leydig cells are mature and abundant, compatible with their proven steroidogenic activity. The mass of smooth muscle attached medially to the testis has the appearance of myometrium but contains no cavity. The lateral appendage of the testis in this syndrome contains both cysts and tubules. Some of the latter have an unmistakably Fallopian construction and from all the evidence McMillan concludes that they are Fallopian in origin.

\section{Discussion}

The clinical features of testicular feminization have been described in detail by Morris (1953) and by Hauser et al. (1957). The mechanism of the defect which leads to the condition is uncertain, although the inherited pattern suggests a single gene defect and consequently an enzyme defect (Polani, 1962). It had earlier been suggested by Morris that the oestrogen might be different from normal in view of the unusual tissue response; alternatively there might be target organ resistance to normal circulating oestrogen.

Current work (Deshpande et al., 1965), however, shows that hormone production follows the normal male pattern. Despite this, the testicular sex cells fail to develop normally and the Wolffian system is amost completely suppressed. Müllerian development is inhibited to some extent. Whether these effects are due to an anti-androgen or to some unusual oestrogen produced under genetic direction remains to be discovered.

Vaginal adequacy varies from case to case and there have been few reports of surgical correction. Bulska, Teter \& Ruszkowski (1960) reported on the successful management of one such case. The technique of operation in our case has followed the standard McIndoe-Read procedure, the latter having been recently described and reviewed by Jackson (1965). It appears clear from the experience obtained in our case that the procedure is suitable for surgical correction in cases of testicular feminization where increased length of the vagina is required.

It is of interest that the graft took well despite the hormenal state described.

\section{Summary}

The creation of an artificial vagina in a patient with testicular feminization is described, details of investigations performed and the histo-pathological features being also included.

\section{Acknowledgments}

We would like to thank Dr N. Deshpande, Dr D. Y. Wang and R. D. Bulbrook of the Division of Chemistry and Biochemistry, Imperial Cancer Research Fund, London, and Dr Mary McMillan of this hospital for their biochemical investigations, Professor P. E. Polani of Guy's Hospital for the chromosome analyses, Dr M. O. Skelton for the histo-pathological report and Dr Mary McMillan for access to a histo-pathological account of testicular feminization prior to publication.

\section{References}

Bulska, M., Teter, J. \& Ruszkowski, J. (1960) Formation of the artificial vagina in male pseudohermaphrodite with testicular feminization syndrome. Ginek. pol. 31, 9. 
Deshpande, N., Wang, D.Y., Bulbrook, R.D. \& McMillan, M. (1965) Hormone studies in cases of testicular feminization. Steroids, 6, 437.

Hauser, G.A., Keller, M., Koller, T., Wenner, R. \& GlooR, F. (1957) Testikuläre "Feminisierung" bei Erwachsenen. Schweiz. med. Wschr. 87, 1573.

JACKSON, I. (1965) The artificial vagina. J. Obstet. Gynaec. Brit. Cwlth, 72, 336.

McMillan, M. (1966) Five cases of testicular feminization including one with a teratoma of the testis. J. Path. Bact. (In press).
MORRIS, J.M. (1953) The syndrome of testicular feminization in male pseudohermaphrodites. Amer. J. Obstet. Gynec. 65, 1192.

Polani, P.E. (1962) in: Chromosomes in Medicine (Ed. by J. L. Hamerton). Little Club Clinic Dev. Med. No. 5. National Spastics Society and Heinemann Medical Books, London.

Taillard, W. \& Prader, A. (1957) Etude génétique du syndrome de féminization testiculaire totale et partielle. J. Génét. hum. 6, 13.

\title{
Unilateral tubal twin pregnancy
}

\author{
SYLVESTER KRZANIAK \\ B.M., B.Chir., M.R.C.O.G. \\ Obstetric and Gynaecological Registrar, \\ Central Middlesex Hospital, London, N.W.10
}

INTRAUTERINE twin gestation occurs as often as one in every eighty pregnancies, but ectopic and heterotopic twins are relatively uncommon. The heterotopic variety may take several forms, e.g:

(a) Coexisting intrauterine and tubal pregnancy (Kazman \& Burnett, 1953 ; Goodman, Elia \& Friedell, 1960).

(b) Coexisting intrauterine and abdominal gestation (Zarou \& Sy, 1952; Nandi, 1953).

(c) Bilateral tubal pregnancy (Evans \& Goyanes, 1952 ; Williams, 1957).

(d) Coexisting ovarian and intrauterine twins (Rannels, 1953 ; Lawson \& Chouler, 1955).

Primary ovarian twin pregnancies were reported (Modavi, 1962; Green \& West, 1963). This is the rarest form of twinning.

Unilateral tubal twin pregnancy is still very rare. In 1955 Unger reported one case and, reviewing the world's literature, stated that by then there were only seventy-nine cases. This figure was confirmed by others (Bucklin \& Myint, 1959 ; Borrow \& Schreiber, 1961 ; Loh \& Loh, 1962).

Bucklin \& Myint (1959), however, reported their case as the eightieth, whilst in Loh's (Loh \& Loh, 1962) estimation this was the eighty-third case reported in the literature. Borrow \& Schreiber (1961), on the other hand, said that their two cases brought the total number of unilateral tubal twins to eighty-one cases.

This disparity can be explained by the fact that Bucklin \& Myint (1959) did not take into account three cases published in 1957 and 1958 (Fill \& Ross, 1957; Fara \& Varga, 1957; Demick \& Cavanagh, 1958). Borrow seemed unaware of the above three publications as well as that of Bucklin in 1959, and Loh \& Loh (1962) made no reference to the two Borrow cases.

If the above corrections are made respectively, the total number of published unilateral tubal pregnancies by 1962 was eighty-six.

\section{Case report}

Mrs T.S., 32 years old, Indian, Gravida III, para I, was admitted into the Casualty Department on 4 September 1964 with a history of increasing lower abdominal pain of 1 day's duration, accompanied by nausea. She also volunteered that she had some pain in the right shoulder. This episode was preceded by lower abdominal pain and discomfort of 3 days' duration, 8 days prior to admission.

Her menstruation started at the age of 15 . The periods were regular occurring every 28 days and lasting 4 days. The last menstrual period occurred on 16 June 1964. Her husband had died of 'sudden heart attack' on 26 June 1964 and she attributed her amenorrhoea to shock but a Primodos pregnancy test on 14 August 1964 was positive.

Her only child was born in 1949 the third stage being complicated by a retained placenta. She also had had two abortions at 10 weeks gestation in 1949 and 1954.

There was no history of serious illnesses or operations.

On examination her general condition was satisfactory. The temperature was $99^{\circ} \mathrm{F}$. Her pulse was regular at the rate of $80 / \mathrm{min}$. Blood pressure was $100 / 60 \mathrm{mmHg}$. There was no evidence of shock. The breasts were active. Cardiovascular and respiratory systems were normal. The lower abdomen was slightly distended, the hypogastrium was tender and there was marked rebound tenderness in both iliac fossae. An ill-defined mobile, tender swelling was palpable in the right iliac fossa.

There was no vaginal bleeding or discharge. The uterus was enlarged and corresponded in size to an 8-week gestation. The cervix was congested, closed and there was marked cervical excitatory pain. Both fornices and the pouch of Douglas were very tender.

There was a cystic mobile swelling $10 \mathrm{~cm}$ in 